УдК 340.12(47)(09)

Д. В. Волков

Российская правовая акаделия

Министерства юстиции Российской Федерации, г. Санкт-Петербург, Российская Федерация

С. В. Красильников

Российская акаделия народного хозяйства и государственной службы при Президенте Российской Федераиии, г. Санкт-Петербург, Российская Федерация

\title{
РАЗВИТИЕ ПОДХОДОВ К ПОНИМАНИЮ ВЕРХОВЕНСТВА ПРАВА КАК ОСНОВОПОЛАГАЮЩЕЙ ИДЕИ ПРАВОВОГО ГОСУДАРСТВА В РОССИЙСКОЙ ПРАВОВОЙ МЫСЛИ НАЧАЛА ХХ ВЕКА
}

\begin{abstract}
АНнотАЦия. Данная статья посвящена развитию идеи верховенства права в отечественной юридической мысли начала XX в. Показан переход России к конституционному строю, представлены различные интерпретации концепции правового государства в юридической науке и политической практике и описано ее развитие. Проанализированы труды ведущих государствоведов и административистов начала $\mathrm{XX}$ в., представлявших различные политические взгляды (от монархистов до неолибералов). В результате данного анализа выявлены основные подходы к пониманию сущности правового государства, гарантий верховенства права, корреляции связанности государства правом и защитой прав граждан, рассмотрены ключевые виды классификации структуры правового государства. Предложен авторский вариант порядка воплощения в жизнь принципа верховенства права, обеспечивающий его использование в качестве связующей скрепы, направленной на политическое единство. кЛЮЧЕВЫЕ слОВА. Государственный строй; правовое государство; верховенство права; право дореволюционной России; общая теория права.

ИНФОРМАЦИЯ О СТАТЬЕ. Дата поступления 25 декабря 2015 г.; дата принятия к печати 26 февраля 2016 г.; дата онлайн-размещения 31 мая 2016 г.
\end{abstract}

D. V. Volkov

Russian Law Academy, Ministry of Justice of the Russian Federation, Saint-Petersburg, Russian Federation

S. V. Krasilnikov

Russian Academy of National Economy and Public Service under the President of the Russian Federation,

Saint Petersburg, Russian Federation

\section{DEVELOPING APPROACHES TO UNDERSTANDING SUPREMACY OF LAW AS A FUNDAMENTAL IDEA IN RUSSIAN LEGAL THOUGHT IN EARLY XX CENTURY}

ABSTRACT. This article focuses on developing the idea of supremacy of law in the national legal thought in early XX century. It shows Russia's transition to the constitutional order, presents various interpretations of the legal state concept in juridical literature and escribes its development. It gives an analysis of works of th leading political scientists and administrative law experts of the early XX century who represented various political views (from monarchists to neoliberals). The analysis resulted in identifying main approaches to understanding the essence of the legal state, guarantees of supremacy of law, correlation of the state's coherence by law and protection of citizens' rights; the article also considers the key types of classification for the structure of the legal state. It offers an author's variant of the procedure for implementing the law supremacy principle providing its use as a binding brace directed at political integrity.

\section{Baikal Research Journal}


KEYWORDS. State system; legal state; supremacy of law, law in pre-revolutionary Russia, general theory of law.

ARTICLE INFO. Received December 25, 2015; accepted February 26, 2016; available online May 31, 2016.

Вследствие проводимых преобразований в современном обществе политическая и экономическая системы Российской Федерации претерпевают существенные изменения. В этой связи остро встают проблемы формирования эффективного механизма обеспечения прав, свобод и законных интересов человека и гражданина, верховенства права, а также оптимального сочетания интересов личности и государства. Сложная криминогенная и социально-экономическая ситуация только усугубляют проблемы построения правового государства. Необходимость разрешения указанных проблем обуславливает интерес к самой концепции правового государства, а также к теоретическому осмыслению и практическому воплощению принципа верховенства права как базовой идеи правового государства.

Единой общепринятой концепции правового государства в юридической науке и политической практике не существует. Различные ее интерпретации зависят от характера понимания природы государства и права в их взаимосвязи.

В политической мысли России начала XX в. понятие «правовое государство» имело глубокое содержание, и многими отечественными юристами рассматривалось как наилучший государственный строй [1, с. 199]

Русская правовая мысль XIX и начала XX в. находилась под сильным влиянием европейского юридического мировоззрения эпохи Просвещения, которое культивировало рациональность государственной власти и обосновывало такую модель государства, где равные субъекты обладали бы определенными правами и свободами, защищенными от произвольного государственного вмешательства.

Господствующая в России начала XIX в. историческая школа права отвергала теорию обязательного соответствия «национального права универсальным естественным нормам» [2, с. 50], а следствием этого было «отрицание каких бы то ни было ограничений для царских указов и установлений» [3, с. 12]. В результате произошедшего в Европе во второй четверти XIX в. кризиса «юридического мировоззрения» в России также произошли радикальные изменения в политико-правовых взглядах на соотношение государства и права, которые, по мысли известного философа Н. А. Бердяева, были по-настоящему оценены только в начале XX в. При этом проблематика мысли значительно усложнилась, в нее вошли новые веяния, новые элементы. В России начала XX в. формируется настоящий культурный ренессанс [4, с. 133]. Важно отметить, что Россия переживает расцвет не только в поэзии, философии, но и в юридической науке, что повлекло за собой активное развитие политико-правовых теорий, ключевой из которых являлась концепция правового государства.

Проблема правового государства, по политическим взглядам многих отечественных исследователей, отличается далеко идущим правовым самоограничением [5, с. 54]. В России вопрос построения правового государства был напрямую связан с проблематикой перехода к конституционному строю. Многочисленные программы преобразования государственного строя во всем своем многообразии были направлены в конечном итоге на превращение российского государства в правовое государство.

С. А. Котляревский отмечал, что «если, с одной стороны, осуществление правового государства находит безусловный предел в изначальных свойствах всякой государственной организации и в присущей ей потребности самосохранения, то, с другой, ценность его определяется ценностью самого правового начала» [6, с. 45]. По его мнению, правовое государство является воплощением принципа верховенства закона, «смысл этого верховенства получается при том предположении, что

\section{Baikal Research Journal}


закон справедлив и способ его создания есть в то же время <...> при недостатках человеческой природы обеспечение этой справедливости» [Там же, с. 350].

При этом верховенство закона является важнейшим проявлением основной черты конституционного государства - господства права; оно не тождественно господству права, но составляет главную составную часть его. Господство права выражается, по мнению Б. А. Кистяковского, в трех элементах, присущих организации любого современного конституционного государства:

- вся деятельность высших органов государственной власти должна быть подчинена конституции или иному основному закону;

- за конкретной личностью в современном правовом государстве признается установленная сфера присущих этой личности прав, называемых права человека и гражданина, которые ограничивают произвол государственной власти;

- законодательство в современном государстве должно быть согласовано с народным правосознанием, а для этого законодательные органы должны формироваться в нем путем народного представительства [7, с. 178-179].

Сочетание этих трех элементов, по мысли Б. А. Кистяковского, должно гарантировать верховенство закона и правовой характер современного государства. В своих трудах он также отмечал связанность государства правом, подразумевая под этим не только связанность государства позитивным правом, т. е. не только тем правом, которое само государство устанавливает своей законодательной деятельностью, но и тем правом, которое живет лишь в сознании народа и еще не получило точного выражения в нормах официально действующего права [8, с. 84].

Современник С. А. Котляревского и видный государствовед Н. И. Палиенко указывал на необходимость абсолютного господства права во всех сферах государственной жизни, необходимость отрицания всякого абсолютизма и произвола власти, «бесправия подвластных», и не только в области частных отношений, но и в области политической, в отношениях государственной власти и граждан [9, с. 148].

Один из основоположников конституционного права России Ф. Ф. Кокошкин сущность правового государства понимал в связанности государства правом. При этом с его точки зрения связанность правом присуща не только конституционному государству, но и деспотическому, поэтому ключевой особенностью именно конституционного государства является гарантированный характер его подчинения праву. Только в этом случае государство правовое и государство конституционное отождествляются. Члены государства имеют не только обязанности, но и права, являются не только подданными, но и гражданами.

По его мнению, важнейшей гарантией законности является соответствие закона первоначальному источнику всякого права - народному правосознанию [10, с. 261-262]. Только такое конституционное государство может быть правовым, которое в своих отношениях к подданным связано правом. Можно свести вывод, который делает Ф. Ф. Кокошкин, к следующему: государственная власть основывается на праве и им же и ограничена. Абсолютными гарантиями (и в то же время юридическими ограничениями) для современных цивилизованных государств являются:

- международное право [11, с. 11];

- основные начала государственной организации;

- основные права граждан.

Дореволюционный государствовед В. М. Хвостов тоже являлся сторонником концепции правового государства. Однако он не абсолютизировал учение о правовом государстве в своих политико-правовых взглядах и рассматривал правовое государство более узко и материально, считая, что оно должно позаботиться об охране своей «внешней безопасности, об установлении прочного и справедливого правопорядка внутри страны» [3, с. 46].

\section{Baikal Research Journal}


В. М. Гессен под правовым государством понимал такое государство, которое признает в качестве обязательных для себя как правительства юридические нормы, создаваемые им же в роли законодателя. Правовое государство, продолжал русский мыслитель, «в своей деятельности, в осуществлении правительственных и судебных функций связано и ограничено правом, стоит под правом, а не вне и не над ним» [12, с. 11]. Подчинение праву есть подчинение нормам, установленным законом, ибо законодательная деятельность государства не связана правом, ни положительным, ни обычным, [Там же, с. 114].

Возможность существования современного правового государства он видел через призму государства конституционного. Государство, по его мнению, осуществляет двоякого рода функцию, при этом правовое и конституционное государство у него являются синонимами. С одной стороны, государство законодательствует; государственная власть является своего рода творцом положительного права. С другой стороны, то же государство управляет, действует, осуществляя свои интересы, в пределах им же самим создаваемого права [Там же, с. 11].

А. И. Елистратов, русский ученый-административист, особое внимание уделял концепции правового государства в работе «Основные начала административного права", в которой противопоставляет полицейское государство правовому. Основой правового государства служит идеал автономии личности, противопоставлявшийся режиму постоянной полицейской опеки над людьми.

В своей работе «Очерк государственного права» он подчеркивает трудности, возникающие на пути к правовому государству: чем больше влияние, гнет абсолютизма в стране, тем с большим трудом возможно утверждение в ней новой конституционной системы правового соподчинения людей. Идея верховенства права находилась в жестком столкновении с господством личного усмотрения властвующих $[13$, с. 3], а последние действовали в силу сложившихся исторических традиций. Борьба противоположных начал полицейского и правового государства, продолжающаяся и в наше время, по его мнению, раскрывается в политическом укладе смешения форм старого и нового типа. Поэтому в правовом государстве, которое исторически приходит на смену полицейскому государству, право приобретает высшее руководящее значение в определении соподчинения людей. По мысли А. И. Елистратова, основные законы становятся верховным связующим началом для всех государственных учреждений и граждан, т. е. получают свойство конституции. Таким образом, монарх утрачивает единоличную государственную власть. Равная связанность законом ставит в правовом государстве граждан и должностных лиц в равное положение; они все подчиняются закону, а не усмотрению или произволу властвующих лиц.

Закон, отмечает А. И. Елистратов, имеет источником своей силы правосознание индивида. Закон обязан быть оправдан индивидом, чтобы стать для него законом. При этом в вопросе о верховенстве правового закона авторитет признается за безличными нормами права.

Следует выделить утверждение исследователя о том, что «начало правового суверенитета коренным образом перестраивает государственное соподчинение людей в направлении, благоприятном для свободного развития человеческой личности» $[13$, с. 7].

А. И. Елистратов выделяет определенную структуру правового государства, считая, что структуре правового государства гораздо более соответствует идея верховенства не того или другого лица или группы лиц, а самого права. «В правовом государстве юридически нормы ложатся в основание деятельности не только судебных и административных, но и законодательных учреждений» [Там же, с. 6]. Наличие сомнений в юридической связанности законодательных учреждений является стимулом власти создавать новые юридические нормы, а следовательно, и видоизменять существующий порядок.

\section{Baikal Research Journal}


С точки зрения А. И. Елистратова, верховенство правового закона обусловливается известным юридическим актом, в том числе и законом, который существует для каждого лица и организации лишь до тех пор, пока данный акт имеет законную силу [14, с. 201]. Здесь исследователь справедливо отмечает, что законодательные учреждения подчинены верховенству права, так как до тех пор, пока они в установленном порядке не отменяют того или иного закона, он сохраняет для них, как и для всех и каждого в стране, свою юридическую силу в полном объеме.

По сей день остаются актуальными правовые положения А. И. Елистратова о необходимости создания авторитетного и эффективного международного права. В силу своего предназначения нормативные акты обязаны существовать всюду, где между людьми возможны разногласия, столкновения и споры. При этом государственные границы не должны становиться пределом для развития права. По мнению А. И. Елистратова, потребность в авторитетном и эффективном международном праве стала насущной. Однако существование на каждой государственной территории своего обособленного суверенитета делает удовлетворение этой потребности невозможным.

Отсутствие твердого правового фундамента в отношениях между суверенными властями множества государственных территорий является обратной стороной территориального государственного суверенитета.

С точки зрения В. И. Савальского (в отличие от позиции С. А. Котляревского, Ф. Ф. Кокошкина, А. И. Елистратова) правовое государство неизбежно следует из самой человеческой природы, также как сумма углов в треугольнике неизбежно равняется двум прямым. Уничтожение идеи правового государства есть уничтожение законов природы, но гуманизировать человека, гуманизировать государство это задача вполне посильная. Однако средства для реализации данной задачи находятся не вне государства, а в самом государстве, т. е. в людях. Вне государства невозможны ни этика, ни логика, ни наука, ни хозяйство, словом, никакая культура, - завершает свою мысль В. И. Савальский в работе «Государственное право. Общее и русское» $[15$, с. 190$]$.

Мысль о необходимости подчинить господству обезличенного права казуальные случаи жизни, являвшаяся ключевой для множества сторонников естественно-правовой теории, мысль, безусловно, прекрасная, но при этом она является одним из частных проявлений общей концепции стремления к утверждению права. Право, конечно, должно царить в жизни, «но не право раз и навсегда данное и законченное, а право развивающееся и обновляющееся, право, идущее вперед, навстречу растущим потребностям жизни» [10, с. 441-442].

Характерный представитель дореволюционного русского неолиберализма П. И. Новгородцев рассматривал правовое государство иначе, не считая, что правовое государство может стать идеалом, который может в дальнейшем, по мере развития государства, разрешать возникающие общественные противоречия. Обосновывая необходимость связанности государства правом, П. И. Новгородцев считал необходимым признать «некоторую норму, стоящую над государством» [Там же, с. 439].

В отдельных случаях она будет выступать в качестве «высшей нормы», в других случаях как «норма естественного права», или «норма нравственная». Под связанностью государства правом П. И. Новгородцев понимает вытекающую из принципов обязанность, а не фактический самоограничитель, зависящий от произвола [10, с. 440].

Многие известные юристы и правоведы России начала XX в. склонялись к мысли о том, что правовое государство должно базироваться исключительно на праве, и в нем должно осуществляться безусловное господство права. Отстаивая тезис «все, что не воспрещено законом, то разрешено», они понимали запреты как положительные предписания с позиций справедливости. [2, с. 57]

\section{Baikal Research Journal}


В полноценном, развитом правовом государстве право и государство взаимно обуславливают друг друга, многообразно переплетаются, дополняя друг друга и созидая. «Каждое из них, постоянно меняясь ролями с другим, как бы является попеременно то причиной, то следствием другого» [7, с. 611].

Важно отметить, что, не смотря на многообразие подходов к его пониманию, принцип верховенства права собирательно символизирует ключевые аспекты правового государства. Его суть состоит в том, что государственные решения должны быть основаны на согласии свободного гражданского общества. Следовательно, они призваны защищать фундаментальные права и свободы граждан, являясь при этом объектами оценки независимых судов. Следует согласиться с мнением ученых, считающих, что «правового регулирования в строгом смысле слова (а правовое регулирование есть не что иное, как установление должного поведения в рамках, определяемых правовыми законами) просто нет там, где отсутствуют права человека» $[16$, c. 121]. С точки зрения соотношения личности, общества и государства, принцип верховенства права исходит из приоритета права по отношению ко всем структурным элементам политической системы и установления "юридического» равенства субъектов, в основе которого лежит требование безусловного подчинения (со стороны всех субъектов и, в первую очередь, самого государства) требованиям правовых норм. Правовой закон при таком подходе рассматривается как одинаковая, равная мера свободы для правящих и подвластных. Однако если для гражданина его верховенство определяется формулой «разрешено все, что не запрещено законом», то в отношении государственной власти, подчиняющейся этому же закону, действует другое правило "разрешено только то, что разрешено законом».

В соответствии со ст. 4 Конституции РФ Конституция и федеральные законы имеют верховенство на всей территории РФ. Все другие правовые акты всех уровней, принимаемые в Российской Федерации, не должны противоречить Конституции РФ (ст. 15).

Закрепление главенствующей роли права означает презумпцию правовой природы закона, действующего в государстве, и поэтому данный нормативный акт подлежит обязательному выполнению всеми субъектами правоотношений (и, в первую очередь, самим государством). При этом несомненно, что государство, не вправе нарушать изданный им же закон, но обладает возможностью изменить или отменить его в установленном порядке. Однако подобная возможность государства ограничивается нормативно-правовыми предписаниями.

Собирательно принцип верховенства права символизирует собой важнейшие аспекты правовой государственности. Говоря о соотношения государства, общества и личности принцип верховенства права закрепляет «юридическое» равенство субъектов, декларирует абсолютный приоритет правовых норм по отношению ко всем социальным регуляторам и безусловное подчинение требованиям правовых норм всех, в том числе и самого государства. В рамках данного подхода право является единообразной мерой свободы для правящих и подвластных. При этом поведение отдельного гражданина определяется формулой «разрешено все, что не запрещено законом», а в отношении подчиняющейся этому же закону государственной власти действует другая формула - «разрешено только то, что разрешено законом».

В сфере законодательной и правоприменительной деятельности принцип верховенства права означает, что при возникновении противоречия между предписанием, установленном в нормативном правовом акте и требованием государственной целесообразности государство должно подчиняться требованиям нормативного правового акта. Государственная целесообразность является одним из факторов, которые оказывают существенное влияние на порядок внесения изменений в действующее законодательство (внесение поправок в нормативные правовые акты, отмена

\section{Baikal Research Journal}


старых и принятие новых нормативно-правовых актов), вместе с тем этот порядок предполагает строго определенную процедуру законотворчества, нарушение которой признается противоправным поведением и влечет за собой ответственность.

Воплощение в жизнь принципа верховенства права, на наш взгляд, осуществляется путем проведения следующих мероприятий:

- закрепление в нормативно-правовых актах общеобязательных правил поведения;

- соблюдение иерархичности нормативно-правовых актов;

- обеспечение юридического равенства субъектов (включая и само государства) перед законом и судом;

- обязательное исполнение содержащихся в нормативных правовых актах требований всеми лицами, подпадающими под действие данных актов;

- улучшение качества действующих и принимаемых нормативных правовых актов с учетом потребностей юридической практики и юридической техники.

Таким образом, можно утверждать, что идея господства права оказывается той связующей скрепой, которая, в конечном счете, обеспечивает политическое единство. Взаимоотношения в политике определяются господством и подчинением, так как политика по своей сущности есть борьба за власть. Право становится производной категорией политики, а принцип свободы индивида заключается в его неотъемлемом праве бороться за власть согласно его разумно-эгоистической природе, будучи ограниченной легитимным общественным договором. Идея верховенства права есть должное, но такое должное, которое дает ориентир в рассмотрении сквозь призму составляющих ее понятий конкретных проблем.

\section{Список использованной литературы}

1. Чуксина В. В. Специализированные российские правозащитные институты: история и современность / В. В. Чуксина // Дни науки - 2009 : материалы науч.-практ. конф. ф-та гос. и междунар. права. - Иркутск : Изд-во БГУЭП, 2009. - Ч. 1. - С. 199-204.

2. Глушаченко С. Б. Русские юристы второй половины XIX - начала XX вв. о правах личности и правовом государстве (историко-правовое исследование) : дис. ... д-ра юрид. наук : 12.00.01 / С. Б. Глушаченко. — СПб., 2000. — 349 с.

3. Хвостов В. М. Общая теория права. Элементарный очерк / В. М. Хвостов. - М. : Унив. тип., 1905. - $211 \mathrm{c.}$

4. Бердяев Н. Русская идея / Н. Бердяев // Вопросы философии. - 1990. — № 1. С. $77-144$; № 2 . - С. 87-154.

5. Венгеров А. «Несущие конструкции» правового государства (Разрозненные заметки о политико-правовых инновациях в советском обществе) / А. Венгеров / Общественные науки и современность. - 1991. - № 5. - С. 19-27.

6. Котляревский С. А. Власть и право. Проблема правового государства / С. А. Котляревский. - М. : Тип. «Мысль», Н. П. Меснянкин и Ко, 1915. - 419 с.

7. Кистяковский Б. А. Социальные науки и право. Очерки по методологии социальных наук и общей теории права / Б. А. Кистяковский. - М. : М. и С. Сабашниковы, типо-литогр. т-ва И. Н. Кушнерев и Ко, 1916. - 704 с.

8. Кистяковский Б. А. Государственное право (Общее и русское) : Лекции Б. А. Кистяковского, читанные в Московском коммерческом институте в 1908/1909 академическом году / Б. А. Кистяковский. - М. : Тип. «Московская», 1912. - 800 с.

9. Палиенко Н. И. Правовое государство и конституционализм / Н. И. Палиенко // Вестник права. - 1906. - Кн. 1. - С. 152-163.

10. Новгородцев П. Государство и право / П. Новгородцев // Вопросы философии и психологии. - М., 1904. - Год XV, кн. 74 (IV). - С. 397-450.

11. Машкина А. Ю. Доказательства общепризнанности норм международного права / А. Ю. Машкина // Норма права: проблемы теории и практики : материалы межвуз. круглого стола, проводимого в рамках 69-й конф. преподавателей и докторантов БГУЭП. Иркутск, 25 марта 2010 г. - Иркутск : Изд-во БГУЭП, 2010. — С. 9-15.

\section{Baikal Research Journal}


12. Гессен В. М. Правовое государство и народное голосование: К реформе государственного строя России / В. М. Гессен. - СПб., 1906. - Вып. 2. - 46 с.

13. Елистратов А. И. Очерк государственного права (конституционное право) / А. И. Елистратов. - М. : Тип. и цинкогр. т/д «Мысль», 1915. - 166 с.

14. Сальников С. С. Правовые идеалы судебной реформы в правосознании российского общества второй половины XIX - начала XX века : историко-правовое исследование : дис. ... д-ра юрид. наук : 12.00.01 / С. С. Сальников. - СПб., 2006. - 378 с.

15. Савальский В. И. Государственное право. Общее и русское. Конспект лекций : в 2 ч. / В. И. Савальский. - М. : Тип. «Русского Общества», 1912-1913.

16. Хойман С. Е. Взгляд на правовую культуру предреволюционной России / С. Е. Хойман // Советское государство и право. — 1991. — № 1. — С. 121-123.

\section{References}

1. Chuksina V. V. Specialized Russian human rights institutions: history and modern age. Dni nauki - 2009. Materialy nauchno-prakticheskoi konferentsii [Days of Science, 2009. Materials of Research Conference]. Irkutsk, Baikal State University of Economics and Law Publ., 2009, pr. 1, pp. 199-204. (In Russian).

2. Glushachenko S. B. Russkie yuristy vtoroi poloviny XIX - nachala XX vv. o pravakh lichnosti i pravovom gosudarstve (istoriko-pravovoe issledovanie). Dokt. Diss. [Russian lawyers of the second half of XIX- early XX centuries about personal rights and legal state (historical and legal research). Doct. Diss.]. Saint Petersburg., 2000. 349 p.

3. Khvostov V. M. Obshchaya teoriya prava. Elementarnyi ocherk [General Theory of Law. An elementary Sketch]. Moscow, Universitetskaya tipografiya Publ., 1905. 211 p.

4. Berdyaev N. The Russian Idea. Voprosy filosofii = Issues of Philosophy, 1990, no. 1, pp. 77-144; no. 2, pp. 87-154. (In Russian).

5. Vengerov A. «Supporting structures» of the legal state. (Odd notes of political-legal innovations in Soviet society). Obshhestvennye nauki i sovremennost = Social Sciences and Modernity, 1991, no. 5, pp. 19-27. (In Russian).

6. Kotlyarevsky S. A. Vlast'i pravo. Problema pravovogo gosudarstva [Authorities and Law. Problem of the legal state]. Moscow, Mysl' Publ., N. P. Mesnyankin i $\mathrm{K}^{\circ}$ Publ., 1915. $419 \mathrm{p}$.

7. Kistyakovsky B. A. Sotsial'nye nauki i pravo. Ocherki po metodologii sotsial'nykh nauk $i$ obshchei teorii prava [Social sciences and law. Sketches of methodology of social sciences and general theory of law]. Moscow, M. and S. Sabashnikov Publ., Partnership I. N. Kushnerev i $\mathrm{K}^{\circ}$ Publ., 1916. 704 p.

8. Kistyakovsky B. A. Gosudarstvennoe pravo (Obshchee i russkoe). Lektsii B. A. Kistyakovskogo, chitannye $v$ Moskovskom kommercheskom institute v 1908/1909 akademicheskom godu [State law (General and Russian). Lectures of B. A. Kistyakovky delivered in Moscow Commercial Institute in 1008/1909 academic yearn ]. Moscow, Moskovskaya Publ., 1912. 800 p.

9. Paliyenko N. I. Legal state and constitutionalism. Vestnik prava = Bulletin of Law, 1906, book 1, pp. 152-163. (In Russian).

10. Novgorodtsev P. State and Law. Voprosy filosofii i psikhologii = Issues of Philosophy and Psychology, 1904, Year XV, b. 74 (IV), pp. 397-450. (In Russian).

11. Mashkina A. Yu. Evidences of universal acceptance of international legal standards. Norma prava: problemy teorii i praktiki. Materialy 69-i konferentsii prepodavatelei i doktorantov BGUEP. Irkutsk. 25 marta $2010 \mathrm{~g}$. [Legal standard: problems of theory and practice. Materials of the 69th Conference of Faculty members and PhD Candidates of Baikal State University of Economics and Law. Irkutsk, March 25, 2010]. Irkutsk, Baikal State University of Economics and Law Publ., 2010, pp. 9-15. (In Russian).

12. Gessen V. M. Pravovoe gosudarstvo i narodnoe golosovanie: K reforme gosudarstvennogo stroya Rossii [Legal state and public voting: On reform of Russia's state system]. Saint Petersburg, 1906. Iss. 2. 46 p.

13. Elistratov A. I. Ocherk gosudarstvennogo prava (konstitutsionnoe pravo). [A sketch of public law (constitutional law)]. Moscow, Mysl' Publ., 1915. 166 p.

14. Calnikov S. S. Pravovye idealy sudebnoi reformy v pravosoznanii rossiiskogo obshchestva vtoroi poloviny XIX - nachala XX veka : istoriko-pravovoe issledovanie. Dokt. Diss. [Legal ideals of juridical reform in legal conscience of the Russian society of the second half of XIX - early XX centuries: historical and legal investigation. Doct. Diss.]. Saint Petersburg, 2006. 378 p.

\section{Baikal Research Journal}


15. SavalskyV. I. Gosudarstvennoe pravo. Obshchee i russkoe [Public Law. General and Russian]. Moscow, Russkoe Obshchestvo Publ., 1912-1913. (In Russian).

16. Khoiman S. E. A take on the legal culture of pre-revolutionary Russia. Sovetskoe gosudarstvo i pravo = Soviet State and Law, 1991, no.1, pp. 121-123. (In Russian).

\section{Информация об авторах}

Волков Длитрий Владилирович - кандидат юридических наук, доцент, кафедра конституционного и международного права, Северо-Западный (г. Санкт-Петербург) филиал, Российская правовая академия Министерства юстиции Российской Федерации, 199178, г. Санкт-Петербург, Васильевский остров, 10-я линия, 19A, e-mail: decanat@szfrpa.ru.

Красильников Сергей Владилирович - кандидат юридических наук, доцент, кафедра теории и истории права и государства, Северо-Западный институт управления, Российская академия народного хозяйства и государственной службы при Президенте Российской Федерации, 199178, г. Санкт-Петербург Средний просп., Васильевский остров, 57, e-mail: krasilnikov1966@mail.ru.

\section{Authors}

Dmitry V. Volkov - PhD in Law, Associate Professor, Chair of Constitutional and International Law, the North-Western (Saint Petersburg) Branch, Russian Law Academy of the Ministry of Justice of the Russian Federation, 19A 10-th Line, Vasilyevsky Island, 199178, St. Petersburg, Russian Federation; e-mail: decanat@szfrpa.ru.

Sergey V. Krasilnikov - PhD in Law, Associate Professor, Chair of Theory and History of Law and State, The North-Western Institute of Management, Russian Academy of National Economy and Public Service under the President of the Russian Federation, 57 Sredny Prospect, Vasilyevsky Island, 199178, St. Petersburg, Russian Federation; e-mail: krasilnikov1966@mail.ru.

\section{Библиографическое описание статьи}

Волков Д. В. Развитие подходов к пониманию верховенства права как основополагающей идеи правового государства в российской правовой мысли начала XX века / Д. В. Волков, С. В. Красильников // Baikal Research Journal. - 2016. — T. 7, № 3. — DOI : 10.17150/2411$\underline{6262.2016 .7(3) .22 .}$

\section{Reference to article}

Volkov D. V., Krasilnikov S. V. Developing approaches to understanding supremacy of law as a fundamental idea in Russian legal thought in early XX century. Baikal Research Journal, 2016, vol. 7, no. 3. DOI : 10.17150/2411-6262.2016.7(3).22. (In Russian).

\section{Baikal Research Journal}

